DOI 10.37882/2223-2982.2021.04-2.01

\title{
ПРИМЕНЕНИЕ МЕТОДОВ БЕСПЕРЕВОДНОЙ СЕМАНТИЗАЦИИ ЛЕКСИКИ ПРИ ИЗУЧЕНИИ АНГЛИЙСКОГО ЯЗЫКА КАК ИНОСТРАННОГО В НЕЯЗЫКОВОМ ВУЗЕ
}

\section{APPLICATION OF METHODS \\ OF VOCABULARY SEMANTIZATION \\ WITHOUT TRANSLATION IN THE STUDY \\ OF ENGLISH AS A FOREIGN LANGUAGE \\ IN A NON-LINGUISTIC UNIVERSITY}

S. Alikova

O. Babak

Summary: The article is devoted to the study of some methods of semantization of vocabulary without translation in the study of English in a non-linguistic university. The authors focus on the difficulties faced by students at the stage of study at the university. The principles of selection of lexical material and the peculiarities of introducing new collocations are considered. The authors classify lexical exercises for finding correspondences, reproducing word-formation models and associagrams as effective methods of semantization without translation. The stage of comprehension control can be omitted in groups with a high level of English proficiency, where it will be advisable to move more quickly to conditioned speech exercises.

Keywords: semantization without translation, lexical exercises, associagram, collocation, presentation.

\section{Введение}

K ак известно, английский язык давно закрепил за собой ведущую мировую роль и представляет собой основное средство международной коммуникации. Однако процесс изучения английского языка как иностранного по-прежнему сопровождается рядом сложностей. Преодоление этих сложностей начинается с успешного применения методов введения и закрепления лексического материала, которые являются целью нашего исследования. Актуальность темы данного исследования объясняется перманентными и динамичными изменениями объема и содержания изучаемого материала, что требует пересмотра не только содержания, но и методов и приемов презентации лексического материала, их реструктуризации. При этом нами применялись следующие теоретические и практические методы исследования: анализа методической литературы, синтеза, обобщения, а также наблюдения и сравнения.

Большинство обучающихся владеют основными лек-
Аликова Светлана Викторовна

к.филол.н., дочент, ФГКВОУ ВО «Краснодарское высшее военное авиационное училище летчиков»

kopaeva1979@yandex.ru

Бабак Олег Валентинович

к.п.н., дочент, Кубанский государственный университет obabak@mail.ru

Аннотация: Статья посвящена исследованию некоторых методов беспереводной семантизации лексики при изучении английского языка в неязыковом ВУЗе. Авторы акцентирует внимание на сложностях, возникающих у учащихся к этапу обучения в ВУЗе. Рассматриваются принципы отбора лексического материала и особенности введения новых коллокаций. К эффективным методам беспереводной семантизации авторы причисляют лексические упражнения на нахождение соответствий, воспроизведение словообразовательных моделей и ассоциограммы. Этап контроля понимания может быть опущен в группах с высоким уровнем владения английским языком, где будет целесообразным более скорый переход к условно-речевым упражнениям.

Ключевые слова: беспереводная семантизация, лексические упражнения, ассоциограмма, коллокация, презентация.

сическими и грамматическими навыками, предоставляющими им возможность общения на английском языке. Как правило, коммуникативная компетенция учащихся представлена списком тем, который они проходили в школе. Лексические темы всегда учитывают возрастные особенности учащихся. При обучении в ВУЗе осуществляется переход на более сложные темы, что подразумевает появление специализированной, научной лексики с большим количеством абстрактных существительных, не всегда близких по тематике интересам учащихся. У студентов возникают трудности, обусловленные психологическими и физиологическими причинами:

1. необходимость затраты большего количества усилий для запоминания новых слов;

2. недостаточно интенсивная мотивация, что может являться результатом сформированности базового лексического уровня (и тогда новая лексика представляется излишней для запоминания), а также быть вызвано социальными причинами;

3. склонность к замене новых и более сложных лексических единиц общеупотребимыми синонима- 
ми, которые они уже знают.

Поэтому перед преподавателями ставится задача разрабатывать свои собственные дидактические материалы, призванные обеспечить учеников необходимыми возможностями для расширения словарного запаса.

\section{Способы повышения эффективности обучения}

На наш взгляд, необходимо тщательно подходить к отбору лексического минимума по теме. Как известно, лексика - самый важный компонент речевой деятельности. Без нее невозможно понимать такой вид учебной деятельности как аудирование, читать, писать и, тем более, говорить. Из этого следует вывод, что на каждом уроке лексике необходимо уделять особое внимание, а формирование лексических навыков - одна из главных задач учителя [9, с. 14]. Специалисты советуют принимать во внимание несколько принципов при подборе лексического материала. Во-первых, это тематический отбор. Лексика должна соответствовать изучаемой теме, глоссарий составлен таким образом, чтобы было возможно осуществлять общение по теме. Во-вторых, важна частотность, которую можно проследить посредством словарей, справочников и учебников, а также на популярных тематических интернет-сайтах. В-третьих, большое значение имеет принцип сочетаемости. Чем выше способность лексической единицы, сочетаться с другими словами, тем более коммуникативно ценной она является. Например, глагол to соте является коллокатором в следующих словосочетаниях: come close, come complete with, come direct, come early, come first, come into view, come last, come late, come on time, come prepared, come right back, come second, come to a compromise, come to a decision, come to an agreement, come to an end, come to a standstill, come to terms with, come to a total of, come under attack.

Следует подчеркнуть, что на наш взгляд, коллокации следует вводить с минимальным контекстуальным окружением (в виде предложений) даже на начальном этапе презентации (введения) и выполнения лексических упражнений, на чем мы подробнее остановимся в дальнейших исследованиях [7]. «Многие преподаватели, как правило, сосредоточены на отдельных словах (например, в глоссах и заданиях) и не готовят полезные материалы для повышения уровня осведомленности учащихся о коллокациях. Необходимо подчеркнуть важность повторных экспозиций, которые создают и укрепляют ассоциативные связи между коллокационными составляющими в памяти, обучающийся распознает и использует коллокации как целостные единицы» [1, с. 132]. Важно предоставлять студентам подлинные аудио- и письменные тексты. Для развития коллокативной компетенции обучающимся рекомендуется пройти трехэтапный процесс, который Ф. Газали называет «выявление - фикса- ция - создание». Начальный этап выявления означает осознанное замечание искомых выражений студентами. Преподаватель должен помнить, что пополнение словарного запаса - это не просто изучение новых слов, это часто изучение знакомых слов в новых сочетаниях $[13$, c. 3]. Не следует учить отдельные лексические единицы, вне реального или актуального контекста. Слова должны быть представлены в естественном контексте, в котором они используются. Студенты должны понимать, что слова английского языка не связаны друг с другом случайным образом [12, с. 257]. Если учащиеся не знают о возможных сочетаниях той или иной лексической единицы, они будут продолжать испытывать трудности при аудировании, чтении, говорении и письме [2].

Принцип стилистической неограниченности - принцип принадлежности слова нейтральному стилю, а не литературному, разговорному. Согласно этому принципу, процент лексики повышается с курсом: чем младше курс, тем нейтральнее по стилю лексика. С.Г. ТерМинасова считает целесообразным в учебных целях использовать словосочетания официально-документального и научного стиля. «Функциональный стиль научной прозы по типу словосочетаний характеризуется, с одной стороны, явным преобладанием составных терминов, строго выполняющих свою задачу - дать точное название специальных предметов или явлений, и клишированных словосочетаний, а, с другой стороны - отсутствием абсолютно свободных метасемиотических словосочетаний. Ведущей категорией для словосочетаний функционального стиля научной прозы является категория клишированности» [10, с. 119]. «В учебниках иностранных языков не должно быть ничего лишнего, никакой коннотативности, никакой окказиональности, никаких отступлений от норм, т.е. эти тексты должны моделироваться. Моделированный текст - это такой текст, из которого на строго научной основе изъято, убрано все, что не может быть скопировано, заучено и употреблено иностранцем, в нем каждое слово, каждое словосочетание, а в устной форме - каждый звук представляет собой образец для подражания» [10, с. 124].

Принцип словообразовательной ценности - это принцип способности слов образовывать новые слова с помощью префиксов, аффиксов. Это значит, что преподаватель должен привлекать внимание студентов к словообразовательным моделям, особенно высокочастотным. Так, во время занятий важно уделять время аффиксам, свойственным знаменательным частям речи: существительным, глаголам, прилагательным и др. Желательно равномерно распределить проработку данного лексико-грамматического материала в пределах тематического и временного континуума.

В современный век информационных технологий 
важен также способ презентации и введения новой лексики по теме. Мы используем программу PowerPoint, которая удачно зарекомендовала себя на всех этапах проведения практического занятия по иностранному языку. Согласно утверждению Н.Д. Гальсковой, компьютерная программа PowerPoint зарекомендовала себя как эффективное средство подготовки и демонстрации презентаций не только в сфере бизнеса, но и в образовании. Перечислим очевидные преимущества презентации PowerPoint:

- возможности использования презентации как своеобразной интерактивной, мультимедийной доски, которая позволяет более наглядно семантизировать новый лексический и грамматический (а возможно, и фонетический) материал, а также осуществлять опорную поддержку при обучении всем видам речевой деятельности;

- возможности управления вниманием учащихся за счет эффектов анимации и гиперссылок;

- активизация внимания всей аудитории;

- поддержание познавательного интереса обучающихся, усиление мотивации учения, а также эффективности восприятия и запоминания нового учебного материала;

- возможность в осуществлении контроля за усвоением новых знаний и систематизации изученного материала;

- возможность формирования компьютерной мультимедийной компетентности, как учителя, так и обучающегося, и развития их креативных способностей в организации учебной работы [4].

Е.К. Пыхова считает, что безусловным плюсом презентации, создаваемой в PowerPoint, является возможность варьировать объем материала, используемые методические приемы в зависимости от целей урока, уровня подготовленности целевой аудитории, возрастных особенностей учащихся [8, с. 18].

Приемы введения и закрепления новой лексики тесно связаны с видами языковых упражнений. Существует несколько способов формирования лексических навыков. Одним из них можно назвать работу на слуховой основе. Она включает в себя несколько этапов. На первом - первичное звуковое предъявление слова - главная роль достается учителю, так как новые лексические единицы произносятся им или диктором. Целью этого этапа можно назвать знакомство с произношением новой лексической единицы и подготовка учащихся к ее произнесению, воспроизведению. Лексическая единица может быть произнесена однократно, или же повториться несколько раз, затем воспроизводиться учащимися [9, с. 15].

\section{Методы беспереводной семантизашии лексики}

На начальном этапе для эффективной демонстрации и введения новых лексических единиц мы используем лексические упражнения на основе следующих методов:

1. Лексические упражнения на нахождение соответствий. При этом объяснение слова или словосочетания может быть выражено как на русском, так и на английском языке, в зависимости от языкового уровня учащихся, который, как правило, допускает вербальный способ семантизации. Упражнения на нахождение соответствий являются отличным наглядным примером вербальной семантизации, например, следующее упражнение по теме «Jobs»:

Match the new words with their definitions:

1. nine-to-five job = full-time job

2. flexi-time job

3. to do shift work / to work shifts

4. to do / work overtime

5. part-time job

a) to work extra hours

b) to work at different times, e.g. days one week and nights the next week

c) job with regular working hours (8.30-9.00 a.m. to 5.005.30 p.m.)

d) work can start / finish an hour or so earlier or later

e) job with shortened working day

\section{Find the proper definition:}
1. holiday pay
2. a salary
3. income
4. income tax
5. sick pay
a) the money you earn for your work
b) the money you get before holiday
c) the money you get when you are ill
d) all the money you get in a year
e) part of income you pay to the government

2. Если в рамках лексической темы занятия встречаются аффиксы, свойственные знаменательным частям речи, важно сгруппировать лексические единицы по словообразовательным моделям и наглядно представить студентам, как в следующем упражнении по теме «Jobs»:

\section{Read the words after teacher or speaker:}

Суффиксы -er, -or, -ar указывают на исполнителя действия, профессию или инструмент: trainer, builder, actor, beggar.

Суффикс -eer указывает на род деятельности, про- 
фессию: volunteer - волонтер, pioneer - пионер, engineer инженер, mountaineer-альпинист.

Суффикс -ее у существительных указывает уменьшенную форму от чего-то, на пассивного субъекта действия: employee, trainee, payee.

Суффикс -ess указывает на женский род существительного и присоединяется к глаголам и существительным: waiter - waitress, steward - stewardess, actor - actress.

3. Создание учащимися в тетрадях или на доске мнемоник (схематичных рисунков, ассоциограмм). Ассоциограмма - это графическое, словесное отображение ассоциаций, связанных с изучаемым явлением, понятием, предметом. Так как поток ассоциаций бесконечен и сугубо индивидуален, ассоциограмма позволяет осуществить личностно - ориентированный, развивающий подход к обучению, дает толчок к активной мыслительной деятельности учащихся на уроке [11]. Использование вербальных опор - ассоциограмм или, по определению А.В. Конышевой, семантических блоков, в основе которых лежит принцип полевой методики, способствует осуществлению принципа интеграции знаний в процессе обучения иноязычной лексики, систематизации языкового материала по определённой теме и установлению ассоциативных связей слов, а именно парадигматических, синтагматических и смысловых [6, 2]. При этом осуществляется работа над орфоэпией и орфографией, а также над готовыми словосочетаниями, вырабатываются первичные навыки самостоятельного употребления.

\section{Read, make sentences and draw in your copybooks:}

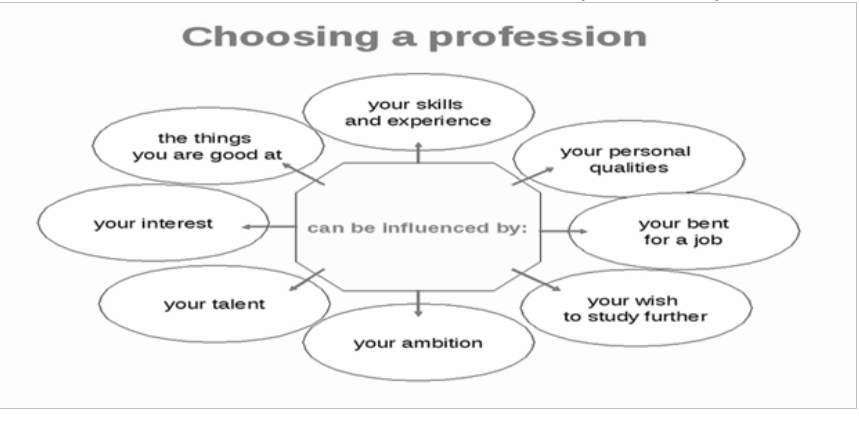

После того, как прошел этап беспереводной семантизации и создания четкого звукомоторного образа слова, можно приступать к контролю понимания [5]. На этом этапе преподаватель может задавать контрольные вопросы, проверяя корректность вторичного воспроизведения. Данный этап может быть опущен в группах с высоким уровнем владения английским языком, где будет целесообразным более скорый переход к условно-речевым упражнениям.

\section{Выводы}

При обучении иностранному языку преподавателю необходимо внимательно подходить к отбору лексики по теме, адаптировать методы ее презентации к уровню учащихся. Как правило, уровень студентов неязыковых ВУЗов позволяет использовать беспереводную семантизацию (например, в форме подбора соответствий), привлечение внимания к продуктивным словообразовательным моделям, представление ассоциограммы, поощряющей мыслительную деятельность.

\section{ЛИТЕРАТУРА}

1. Аликова С.В. Коллокативная компетенция студентов неязыкового ВУЗа: сложности обучения и исследования. Современная наука: актуальные проблемы теории и практики. Серия: Гуманитарные науки. 2020. № 10. С. 130-133.

2. Аликова С.В., Баранова Е.В., Шибкова 0.С. Фразеологизмы в парадигме междисциплинарного подхода. Филологические науки. Вопросы теории и практики. 2016. № 6-2 (60). С. 36-38.

3. Бредихина И.А. Методика преподавания иностранных языков: Обучение основным видам речевой деятельности: учеб. пособие. Уральский федеральный университет. Екатеринбург: Изд-во Урал. ун-та, 2018. 104 с.

4. Гальскова Н.Д. Современная методика обучения иностранным языкам: Пособие для учителя. М: АРКТИ, 2003. 192 с.

5. Жукова Н.А. Практический курс методики обучения иностранному языку. Практикум. Барнаул, ФГБОУ ВО «АлтГПУ», 2020. 107 с.

6. Конышева А.В. Игровой метод в обучении иностранному языку. Санкт-Петербург: КАРО, 2008. 179 с.

7. Копаева С.В. Фразеологизмы в языке немецкой молодежи. Дисс. на соиск. ученой степени к. филол. н., Пятигорский государственный лингвистический университет. Пятигорск, 2005.

8. Пыхова Е.К. Советы по созданию ученических (и не только) компьютерных презентаций по английскому языку. URL: http://pedsovet.org/forum/topic 499. html (дата обращения: 23.01.2020)

9. Ступникова С.А. Формирование лексических навыков у учащихся на основе мультипликационного фильма «Зверополис». Выпускная квалификационная работа, УгпУ. Екатеринбург, 2017.81 с.

10. Тер-Минасова С.Г. Словосочетание в научно-лингвистическом и дидактическом аспектах: Учеб. пособие для пед. ин-тов и филол. фак. ун-тов. - М.: Высш. школа, 1981. 144 с.

11. Черкас Ш. Ассоциограмма в контексте современного урока. URL: https://pandia.ru/text/78/029/8361.php (дата обращения: 25.01.2021) 
12. Ghazali Fawzi Al Reinforcing Students' Collocational Competence in EFL Classrooms. MJAL, 2015. p. 244-261.

13. Woolard, G. Collocation: Encouraging Learner Independence. In M. Lewis (ed.), Teaching Collocation: Further Developments in the Lexical Approach. Hove, UK: Language Teaching Publications. 2000. pp. 28-46.

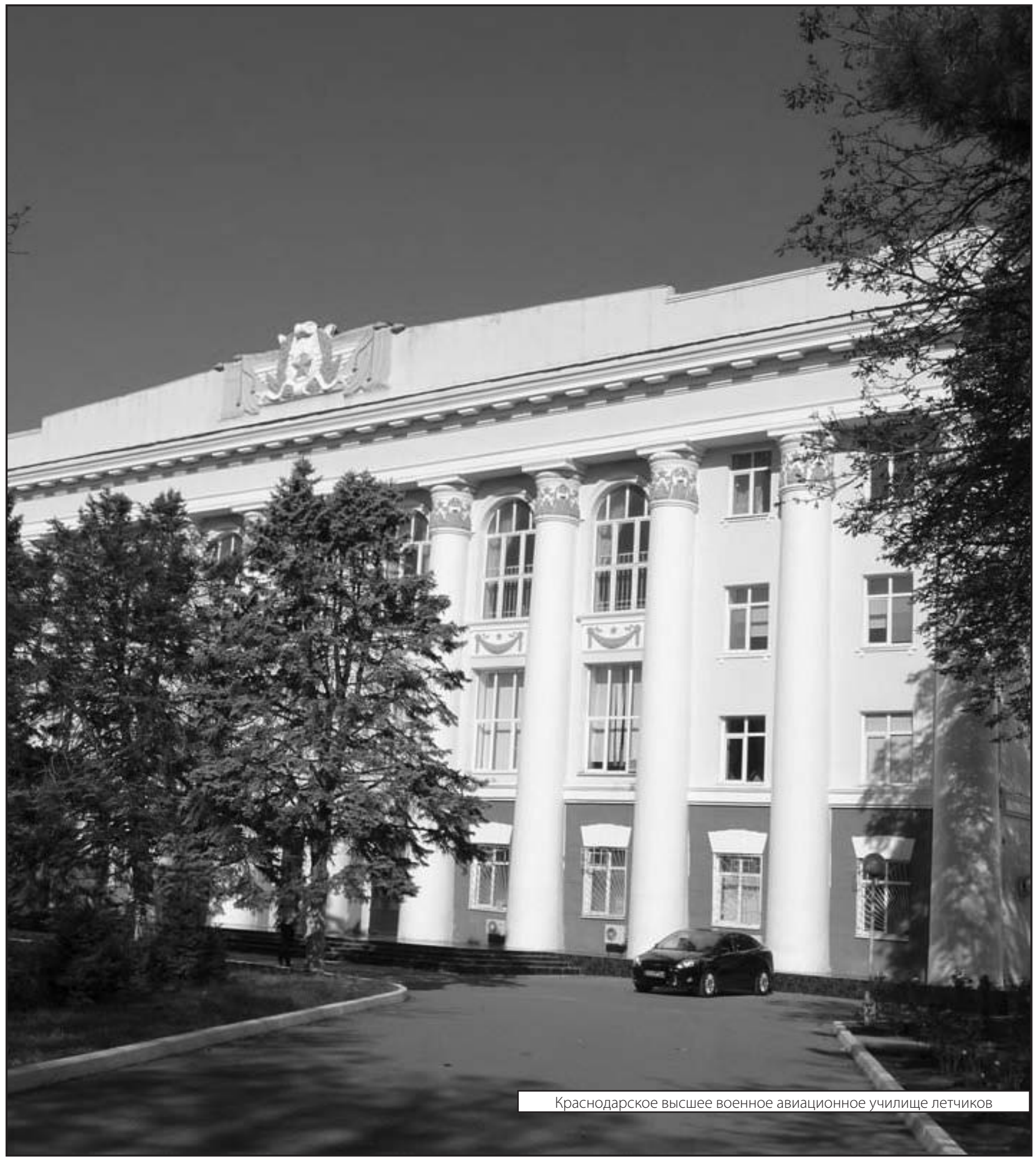

